\title{
Blocos de Fundações de Edifícios Afetados por Reação Alcalis-Agregado (RAA): Estudo de Caso
}

\author{
Title: Foundations of building block saffected by RAA: Case Study \\ Diógenes Tavares de Araújo \\ Escola Politécnica de Pernambuco \\ Universidade de Pernambuco \\ Recife, Brasil \\ diogenes_tavares@yahoo.com.br \\ Carlos Welligton de Azevedo Pires Sobrinho \\ Escola Politécnica de Pernambuco \\ Universidade de Pernambuco \\ Recife, Brasil \\ carlos@itep.br
}

\begin{abstract}
Resumo Muitos prédios residenciais apresentam problemas ao longo do tempo, gerando preocupações e questionamentos dos moradores quanto à segurança e à solidez da edificação. Esse fato é consequência da grande incidência de fissuras em blocos de estacas de fundações nos edificios, representando perigo aos moradores. O presente artigo analisa a existência de reação álcalisagregado-RAA como principal agente causador dos quadros típicos de fissurações encontradas nos blocos de fundações das referidas edificações e que, muitas vezes, podem se somar a outras manifestações patológicas ou até mesmo potencializar outros mecanismos de fraturas. Este artigo mostra o caso de uma estrutura predial localizada na região metropolitana do Recife, onde tivermos 30 casos similares, com resultados de caracterização petrográfica, de resistência à compressão e de módulo de deformação dinâmico do concreto, assim como em análise de microscopia eletrônica de varredura. Os resultados mostram que os agregados graúdos são potencialmente reativos aos álcalis do concreto e, na microscopia eletrônica, são verificados indicativos fortes de reação na interface da pasta/agregado graúdo, além de outros indicativos materializados na queda de resistência à tração e na diminuição do módulo de deformação longitudinal nos testemunhos do concreto. Uma vez diagnosticada a patologia RAA, a solução apresentada ao caso em estudo se refere reforço dos blocos, conforme será demonstrado nesse artigo.
\end{abstract}

Palavras-Chave: blocos fundação; patologias de RAA; degradação concreto

\begin{abstract}
Problems may appear in some residential buildings over time. This fact has raised concerns and subsequent questions from residents regarding safety and robustness of those buildings. The great incidence of cracks and fissures in these buildings' foundation pillar, demands further studies on causes and consequences of this phenomenon. This is required in order to avoid and solve risks or danger that they may cause. This article aims to analyze the existence of alkaliaggregate reaction (AAR) as the main reason for the typical frames of the cracks found in the foundations of these builtings which, in many times, together with other pathological aspects, can increase fracture mechanisms. This article presents a case that addresses building structures located in metropolitan area of Recife. The results of these investigations is based on petrographic characterization tests of compressive strength of concrete and dynamic modulus of elasticity as well as in analysis of scanning electon microscopy. It was also noted that the coarse aggregates are potentially reactive to concrete alkali, and in electron microscopy, there is indicative of strong reaction in the folder interface / coarse aggregate, and other indicative materialized in tensile strength loss and decreasethe longitudinal modulus of elasticity in the concrete testimonies. Once diagnosed the AAR pathology, the solution presented in case study refers strengthening of the blocks, as will be demonstrated in the article.
\end{abstract}

Keywords: foundation blocks; AAR's pathologies; concrete degradation 


\section{Introdução}

A segurança em edificações residenciais, sobretudo naquelas que apresentam manifestações patológicas não previstas em projetos, porém visíveis ao longo do tempo tais como fissuras, desplacamentos e manchas é preocupação fundamental de qualquer profissional de engenharia, que tem prévio conhecimento de que a forma e a intensidade das fissuras podem revelar tendências de movimentação e deformação da estrutura provenientes de processo de degradação dos materiais ou de sua relação com o meio.

Estudos recentes têm comprovado, cada vez mais, que estruturas de concreto que vivenciam frequentes condições de umidade podem apresentar fissuras provenientes de reação álcali-agregado. Tal fenômeno resulta de interações químicas, na presença de água, entre a sílica constituinte do agregado e os álcalis presentes no concreto.

O tema escolhido se baseia, portanto, na importância de se diagnosticar a existência da citada reação em estruturas degradadas, a fim de que se possa apresentar a solução mais viável à manutenção da rigidez estrutural.

Para melhor compreensão do assunto, a metodologia utilizada aborda estudo de caso de fissuramento em edificação construída entre 1985 e 1990, localizada na cidade do Recife, com 13 pavimentos. Possui estrutura em pórticos de concreto armado apoiados em blocos de estacas, vedação em alvenaria e cerâmica revestida e assentada com argamassa.

As características das fissuras existentes e o estudo técnico-científico realizado em laboratório confirmaram a hipótese da RAA, conforme será demonstrado ao longo desse artigo, cujo principal objetivo consiste no repasse de informações necessárias à identificação da presença do referido fenômeno, em estruturas degradadas, avaliando o potencial reativo dos agregados empregados nas obras da construção civil, para que se possa chegar à solução mais viável para o problema.

O presente artigo pretende, também, mostrar que, através da utilização de procedimentos específicos, tais como: análise numérica, análise petrográfica e microsco- pia, e análise físico-mecânica dos testemunhos, pode-se atestar, com segurança, a existência da reação álcaliagregado (RAA) como principal agente causador das fissurações encontradas nos blocos de fundações que apresentarem o quadro típico aqui estudado.

\section{Como referenciar}

Por ocasião da troca das placas do piso do pavimento térreo nas garagens, no edifício analisado, observou-se a presença de fissuras localizadas no entorno dos pilares, no piso do pavimento térreo. Não foram observados, entretanto, fissuramentos nas vigas e tampouco nas lajes desse pavimento, o que excluiu a possibilidade de recalque diferencial dos blocos de fundação e direcionou as investigações para outro caminho.

Na medida em que os estudos se aprofundaram, percebeu-se que, na região localizada na zona de tração dos blocos de fundação, tais fissuras se apresentavam cada vez maiores em proporção, afetando, de forma determinante, o piso que se encontrava sobre esses blocos, apesar de não comprometer o comportamento das vigas e das lajes, como já foi dito anteriormente.

Segundo Pires Sobrinho (2012), quadros fissuratórios intensos na parte superior dos blocos de fundações, concentrando-se, exatamente, na região de baixa compressão, com fissuras de aberturas expressivas nos cantos mais extremos são indicativos da presença da RAA. Entretanto, para a confirmação de tal diagnóstico e consequente verificação do comprometimento da estabilidade estrutural do edifício, outros aspectos deverão, necessariamente, ser observados.

\subsection{Análise das fundações in loco}

O edifício estudado possui 33 blocos de fundação, dentre os quais foram escolhidos 4 (quatro), tomando como base, não apenas o projeto estrutural, como também a checagem em campo, verificando-se tanto a medida dos blocos quanto a simetria existente entre os pilares ( $\mathrm{P} 1$, P2, P3 e P4), conforme Planta Baixa para retirada de testemunhos e mostrada na Figura 1. 


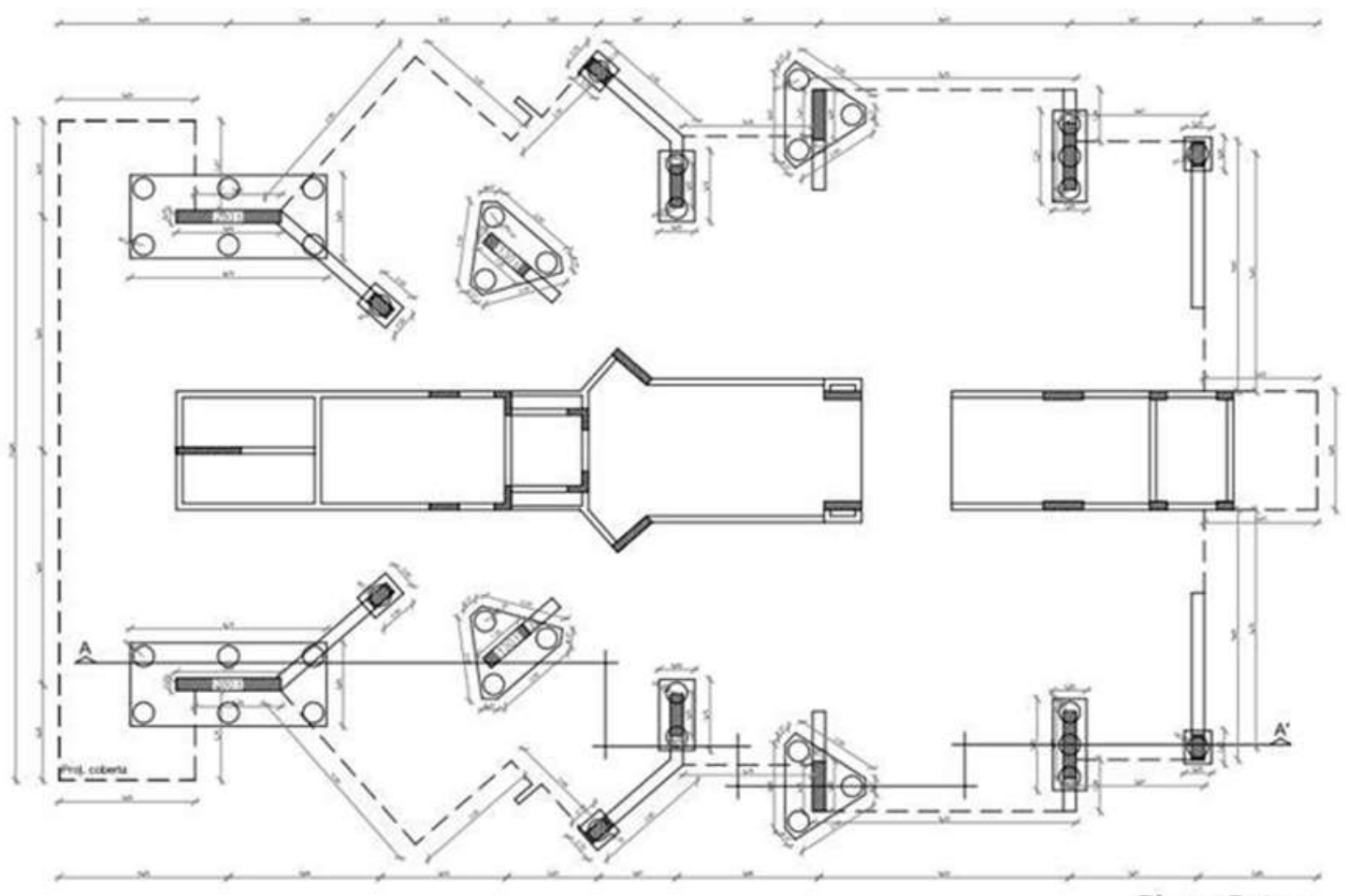

Planta Baixa

Figura 1: Planta baixa, indicando forma e posição dos blocos de fundação

\subsection{Metodologia}

Escolhido quatro pilares: P1 à P4, onde foram realizadas escavações até a profundidade dos blocos de fundação, permitiram a verificação de suas medições, posicionamento das estacas, registro de fissuras, identificação do estado das armaduras e extração de testemunhos do concreto. As Figuras de 2 a 5 mostram as fissuras.

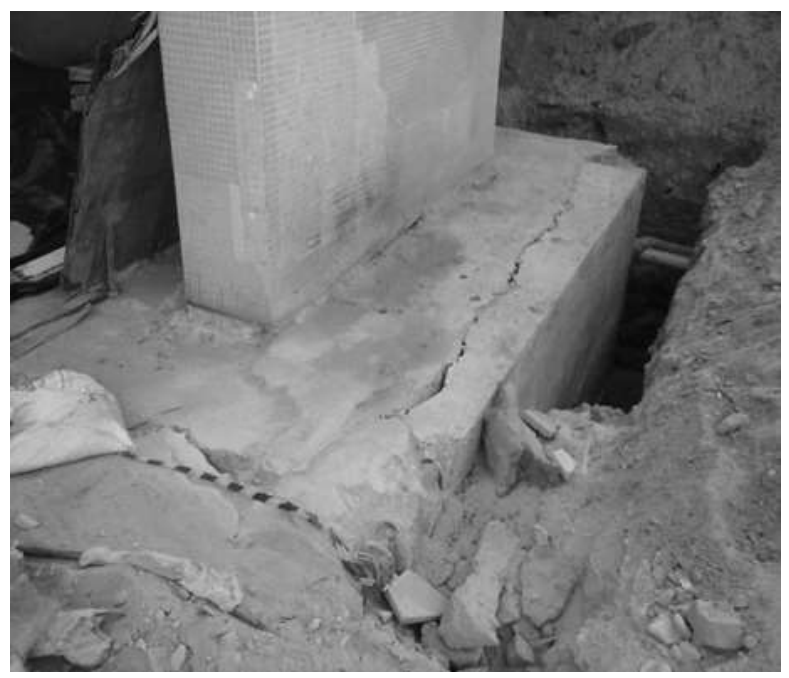

Figura 2: Fissuras na parte superior do bloco
Durante esse processo, observou-se que inúmeras fissuras estavam concentradas nas bases dos pilares mais carregados, ou seja, por sobre os blocos de estacas, na região de baixa compressão, com aberturas mais expressivas nos cantos mais extremos, as quais desciam até a base do bloco, indicando possivelmente a existência de RAA, na fundação.

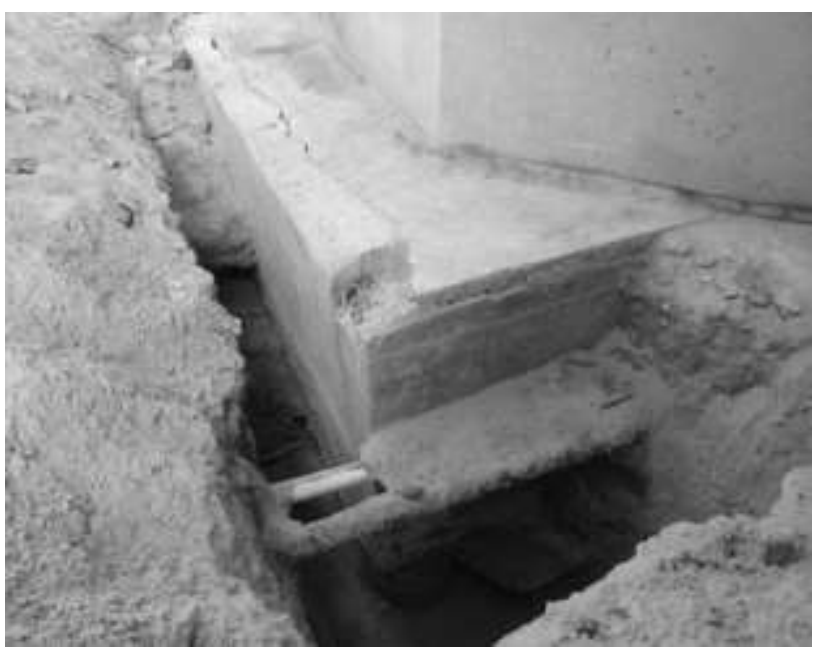

Figura 3: Fissuras concentradas na parte superior do bloco 


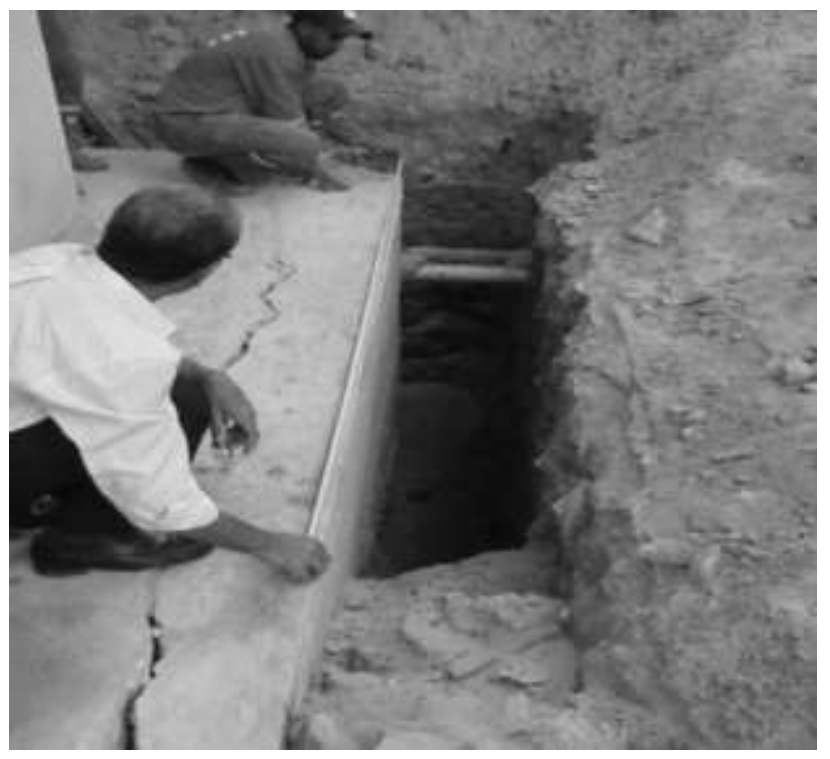

Figura 4: Medições dimensionais

Para a confirmação do precoce diagnóstico, foram retirados testemunhos que foram enviados, tanto para ensaios mecânicos (de compressão e tração) realizados pelo ITEP (Instituto de Tecnologia de Pernambuco), quanto para análise petrográfica e avaliação de microscopia eletrônica, realizadas nos laboratórios da ABCP-SP (Associação Brasileira de Cimento Portland - São Paulo), com o objetivo de verificar a potencialidade reativa dos agregados em presença de álcalis do concreto, conforme estabelecem as seguintes normas: ASTM C 856-04 e ABNT NBR 15577-3/08.

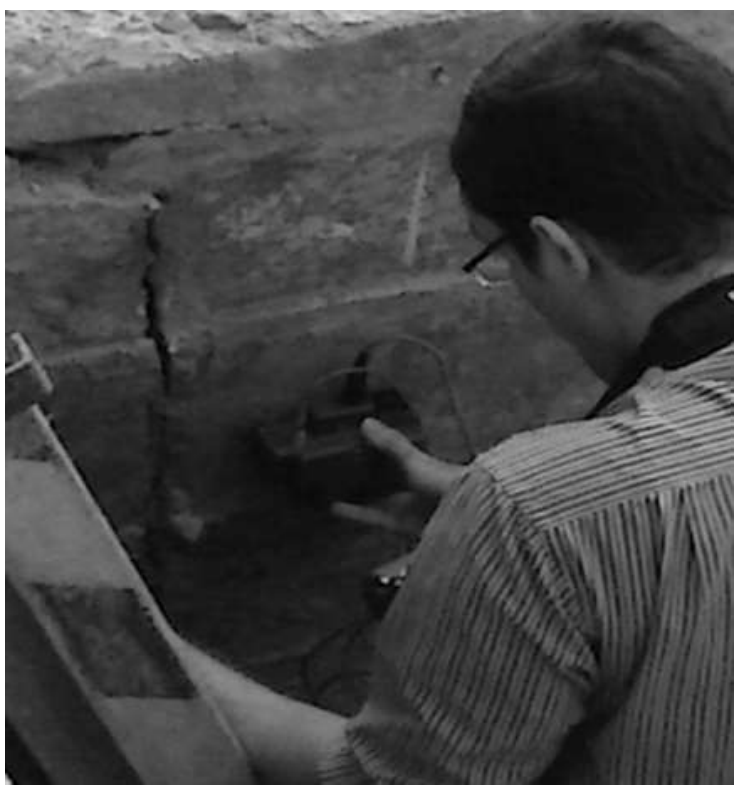

Figura 5: Pacometria para identificar armaduras e cobrimento
Através de máquina própria e em local definido, foram retirados sete testemunhos, ao todo. Dois deles foram encaminhados para análise petrográfica e avaliação de microscopia eletrônica, na ABCP-SP. As Figuras 6 e 7 mostram o processo de retirada.

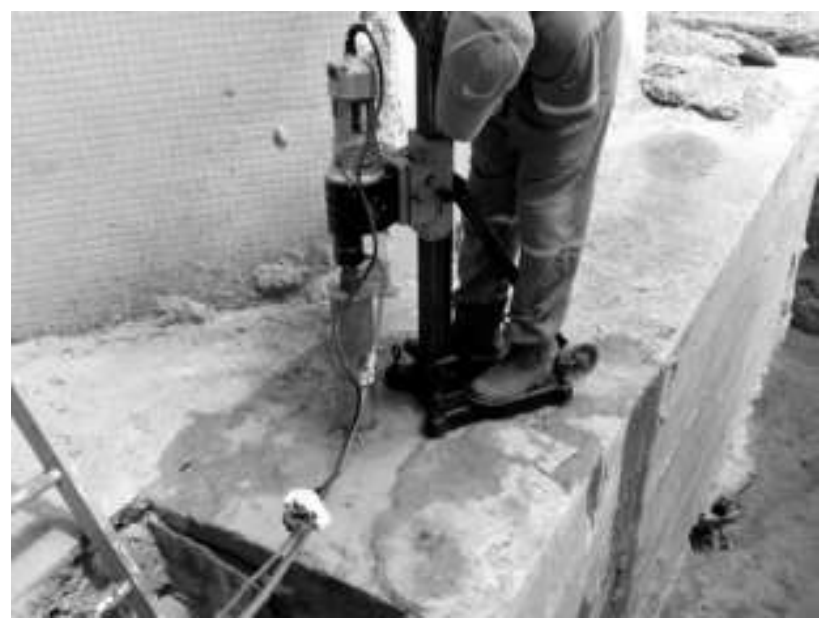

Figura 6: Retirada de testemunho para avaliação da qualidade do concreto

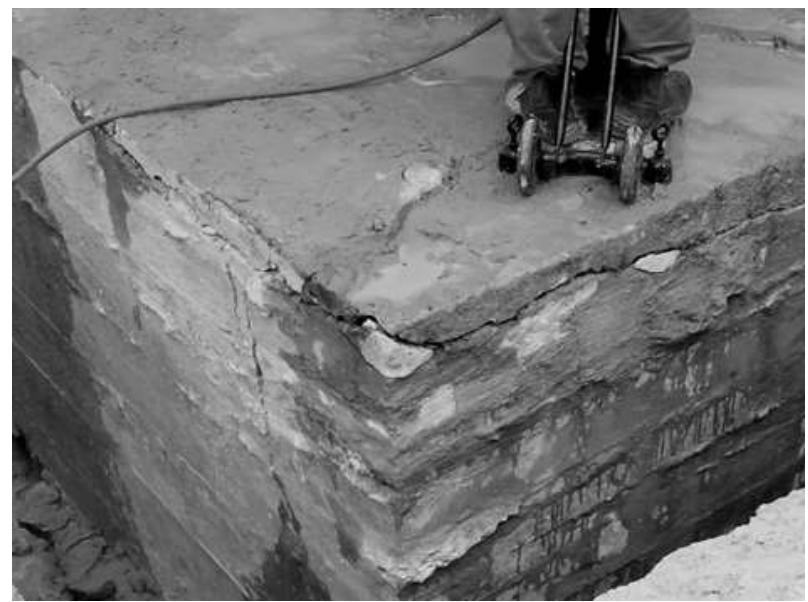

Figura 7: Retirada de testemunhos para avaliação da qualidade do concreto

Observações visuais nos testemunhos mostraram a presença de gel branco em volta dos agregados, nos poros do concreto, revelando que a textura dos agregados graúdos referia características que demonstravam ser potencialmente reativos aos álcalis do concreto, conforme as Figuras 8 e 9, as quais mostram o aspecto da borda de reação, no entorno do agregado graúdo e o aspecto de um poro da argamassa preenchido por etringita. 


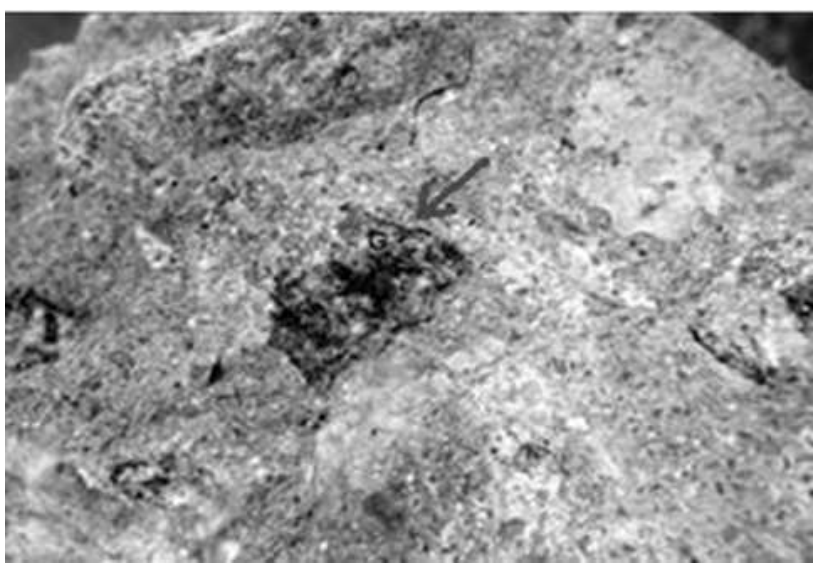

Figura 8: Superfícies de descolamento do agregado graúdo $(\mathrm{G})$ recoberto com material esbranquiçado (ampliação $6 \mathrm{x}$ )

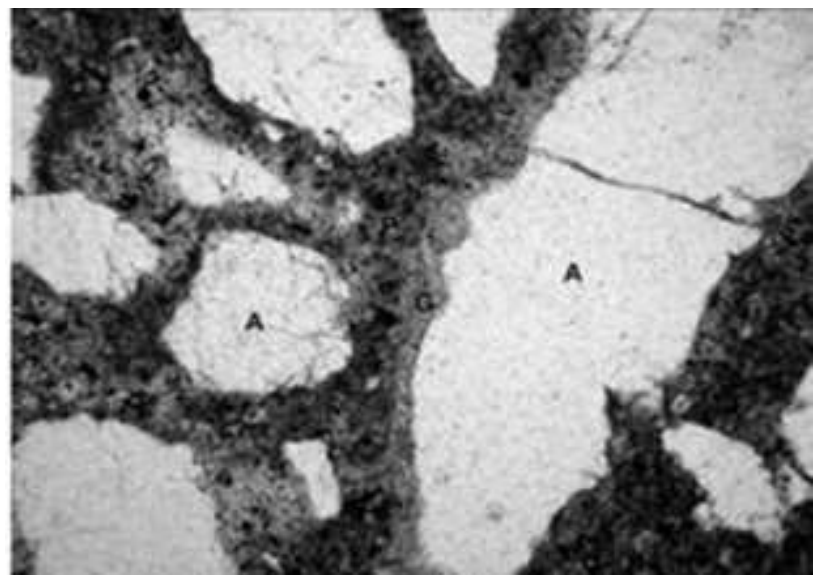

Figura 9: Poro de argamassa (A) preenchido com esbranquiçado e borda preenchida com material gelatinoso $(\mathrm{G})$, gel da reação álcaliagregado, localizado nas bordas do agregado graúdo (ampliação 100x)

\subsection{Análise das amostras em laboratório}

\subsubsection{Análise Petrográfica e Microscópica}

A ABCP-SP (ABCP 2014), utilizando microscópios estereoscópico e óptico para avaliar os resultados relacionados aos aspectos estruturais e de texturas do concreto, observou que suas características macroscópicas demostravam apresentar ele um adensamento adequado (devido à pouca quantidade de vazios de exsudação presentes na amostra), assim como uma boa homogeneização da mistura (devido à distribuição regular dos agregados graúdos em meio à argamassa).

O concreto apresentou, também, baixa porosidade macroscópica. Os poros eram predominantemente milimétricos. Observou-se, ainda, a presença de poros preenchidos por material esbranquiçado maciço, por vezes de aspecto gelatinoso ou por tufos de cristais aciculares de etringita.

A presença da reação álcali agregado foi evidenciada pela constatação, de modo frequente, de bordas de reação em torno de agregados graúdos, associada à deposição de material esbranquiçado nas superfícies de descolamento e quebra do concreto. Verificou-se, ainda, a presença de microfissuras na argamassa.

As Figuras 10 e 11 mostram indícios de RAA observados nos testemunhos retirados dos blocos das fundações. Assim, enquanto a Foto 9 revela o aspecto desse gel expansivo resultante do ataque álcali agregado, a Foto 10 detalha cristais lacetados, resultantes da reação álcalis agregados.

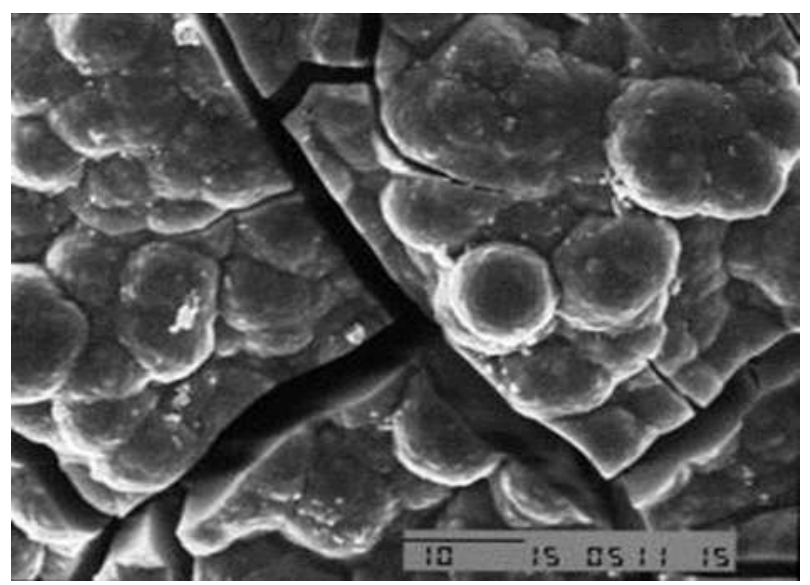

Figura 10: Aspecto gel expansivo

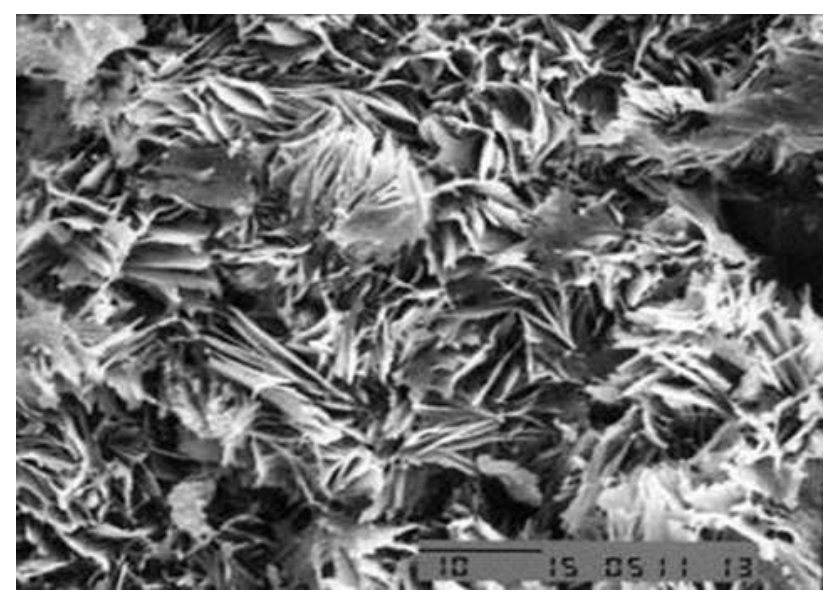

Figura 11: Detalhe de cristais lacetados, resultantes da RAA

Do ponto de vista mineralógico, essas deformações observadas nos agregados graúdos favoreceram o desenvolvimento de reações expansivas do tipo álcali-silicato.

Esse caráter reativo do agregado está fortemente associado à presença de quartzo microgranular e de quartzo fortemente deformado com extinção ondulante. A utilização de microscopia eletrônica de varredura revelou aspectos do gel típicos da citada reação, a partir do qual se desenvolvem os produtos cristalizados, preferencialmente em meio aos grãos de quartzo ou feldspato que constitu- 
em o agregado. A Figura 12 demonstra o aspecto de cristais lacetados, resultantes de uma RAA. Já a Figura 13 informa a composição aproximada e os aspectos dos cristais hidratados obtidos pelo Energy Dispersive Spectrometer (EDS).

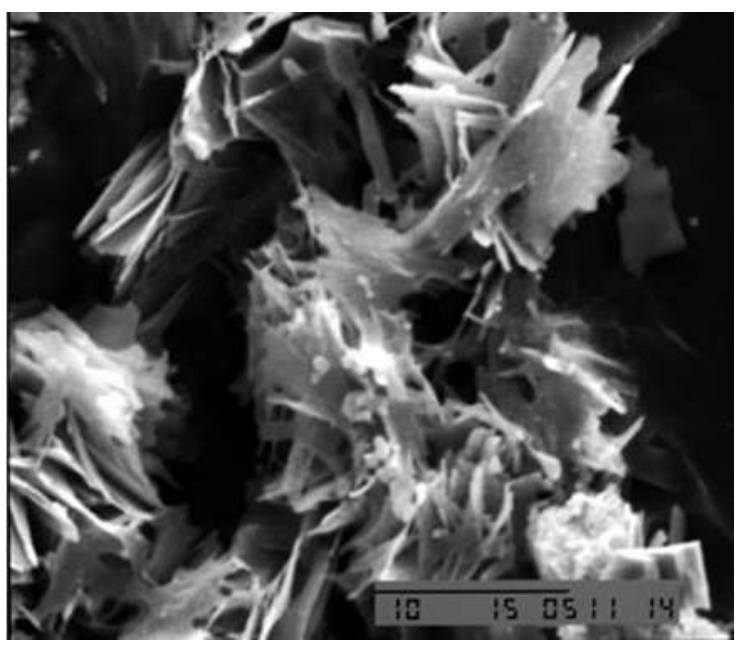

Figura 12: Aspecto de cristais lancetados resultantes de RAA (ampliação 150x)

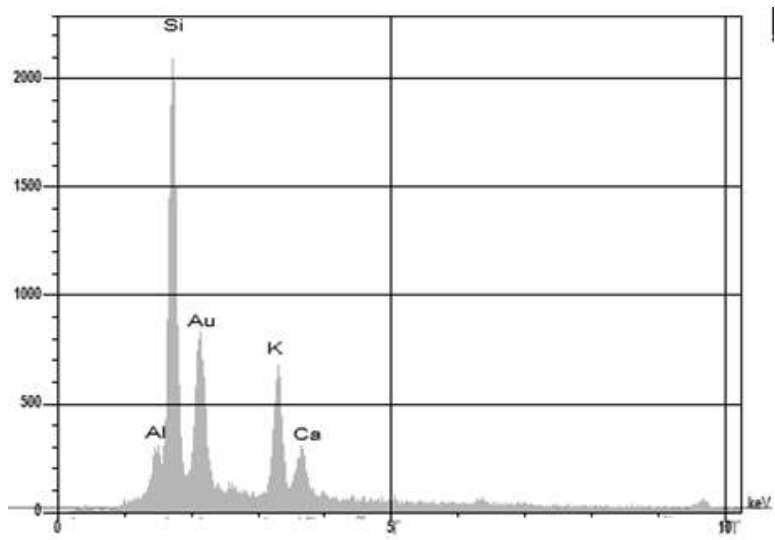

Figura 13: Composição aproximada dos cristais hidratados obtidos pelo EDS

Segundo Figuerôa e Andrade (2008), a RAA é uma reação química que se processa em argamassa ou concreto, entre íons hidroxilas (OH-) associados aos álcalis óxido de sódio (NA2O) e óxido de potássio (K2O) provenientes do cimento ou de outras fontes, como certos tipos de agregados. A reação álcali-agregado é, portanto, um fenômeno químico que ocorre em determinados minerais potencialmente reativos, existentes nos agregados, com presença dos álcalis dos cimentos e com a presença de umidade.

Entretanto, apesar das análises petrográfica e microscópica evidenciarem a indicação de RAA, a confirmação do diagnóstico também necessita da realização de ensaios mecânicos (de compressão e tração), os quais foram rea- lizados pelo ITEP (Instituto de Tecnologia de Pernambuco).

\subsubsection{Análise Físico-mecânica dos Testemunhos}

Para uma melhor determinação da influência da RAA no concreto aqui analisado, os testemunhos restantes foram submetidos à análise de resistência à compressão axial (Figura 14) e à tração na compressão diametral (Figura 15), cujos resultados encontram-se devidamente apresentados nas Tabelas 1 e 2, respectivamente.

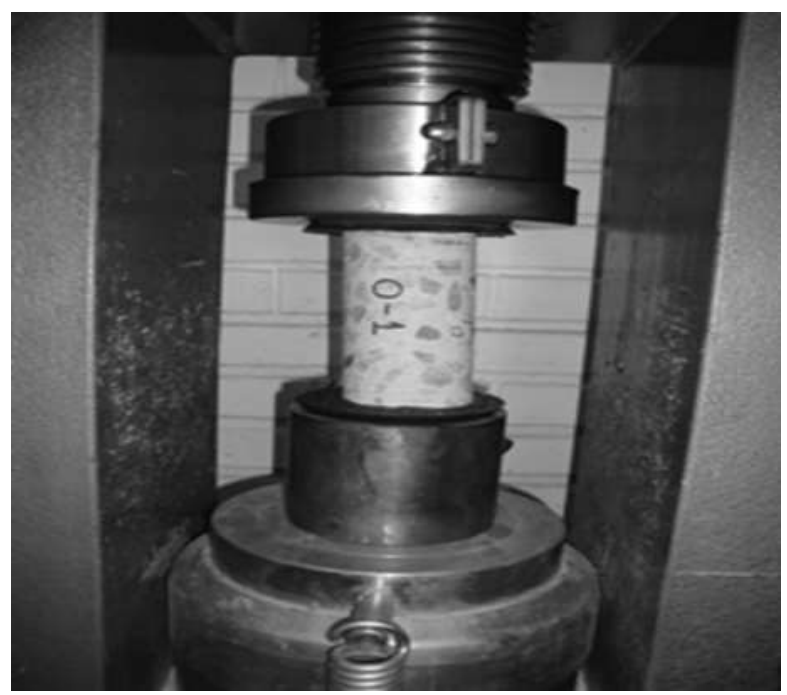

Figura 14: Ensaio de compressão axial [Fonte: Anais do $54^{\circ}$ congresso brasileiro do concreto CBC 2012 , C. W. de A. P. Sobrinho]

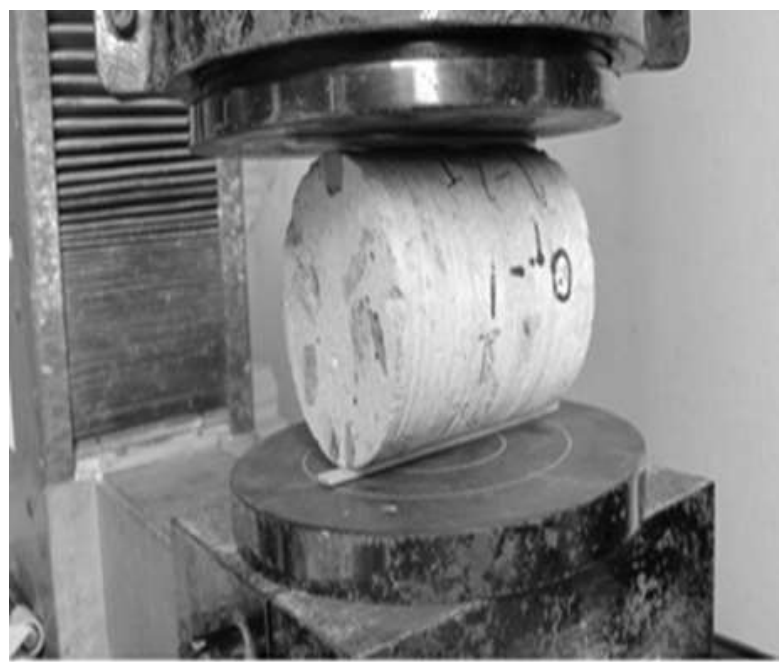

Figura 15: Ensaio de tração diametral [Fonte: Anais do $54^{\circ}$ congresso brasileiro do concreto CBC 2012, C. W. de A. P. Sobrinho] 
Tabela 1: Resultados dos ensaios de resistência à compressão

\begin{tabular}{|c|c|c|c|c|c|c|}
\hline \multirow[t]{2}{*}{$\mathrm{CP}$} & $\mathrm{H}$ & Ǿ & Carga & Resist. & \multirow{2}{*}{$\begin{array}{l}\text { Fator de } \\
\text { correção }\end{array}$} & \multirow{2}{*}{$\begin{array}{c}\text { Resistência } \\
\text { Corrigida } \\
\mathrm{MPa}\end{array}$} \\
\hline & $\mathrm{mm}$ & $\mathrm{mm}$ & $\mathrm{N}$ & $\mathrm{MPa}$ & & \\
\hline 1 & 164 & 100 & 308.8 & 39,32 & 0,97 & 38,14 \\
\hline \multirow[t]{2}{*}{2} & 178 & 100 & 283.8 & 36,14 & 0,98 & 35,41 \\
\hline & & & & & Média & 36,78 \\
\hline
\end{tabular}

$\mathbf{C P}=$ Corpo da Prova

$\mathrm{H}=$ Altura

Ǿ = Diâmetro

Tabela 2: Resultados dos ensaios de resistência à tração por compressão diametral

\begin{tabular}{c|cccc}
\hline $\mathbf{C P}$ & $\begin{array}{c}\mathbf{I} \\
(\mathbf{m m})\end{array}$ & $\begin{array}{c}\text { ठ } \\
(\mathbf{m m})\end{array}$ & $\begin{array}{c}\text { Carga } \\
(\mathbf{N})\end{array}$ & $\begin{array}{c}\text { Resistência } \\
(\mathbf{M P a})\end{array}$ \\
\hline 3 & 135 & 100 & 54.103 & 2,55 \\
4 & 111 & 100 & 56.957 & 3,27 \\
5 & 114 & 100 & 39.864 & 2,23 \\
& & & Média & 2,68
\end{tabular}

$\mathbf{I}=$ Comprimento

Com tais resultados, pode-se fazer um comparativo entre a resistência à tração real (obtida no ensaio) e a resistência à tração estimada, a qual pode ser obtida através da correlação com a resistência à compressão, através da seguinte expressão (MOLIN, 1995):

$$
\begin{aligned}
& \text { FTD = 0,38 x fc0,63MPa } \\
& \text { (válido para 20MPa }<\mathrm{fc}<90 \mathrm{MPa} \text { ) } \\
& \text { Onde: } \\
& \text { FTD = Resistência à tração } \\
& \text { Fc = Resistência à compressão } \\
& \mathbf{M P a}=\text { Mega Pascoal }
\end{aligned}
$$

Através da resistência à tração obtida nos dois corpos de provas da Tabela 1, foram encontrados, por meio da Equação 1, utilizando valor médio de resistência à compressão 36,78. Após obtidos os valores de referência por meio da equação, foram ensaiados três testemunhos à compressão diametral para se fazer um comparativo com as resistências de referência, conforme mostra a Tabela 2 .

A Tabela 3 apresenta a correlação entre os resultados de resistência à tração estimada pela Equação 1 e os resultados daquelas obtidas nos ensaios de tração na compressão diametral.

Tabela 3: Correlação entre resultados de resistência à tração

\begin{tabular}{ccc}
\hline $\begin{array}{c}\text { Resistência à tração } \\
\text { estimada }(\mathrm{MPa})\end{array}$ & $\begin{array}{c}\text { Resistência à tração } \\
\text { obtida em ensaios }\end{array}$ & $\begin{array}{c}\text { Variação } \\
(\%)\end{array}$ \\
3,68 & $(\mathrm{MPa})$ & $-27,2$ \\
\hline
\end{tabular}

Com tais resultados, pode-se fazer um comparativo entre a resistência à tração real (obtida no ensaio) e a resistência à tração estimada, a qual pode ser obtida através da correlação com a resistência à compressão, através da seguinte expressão (MOLIN, 1995):

A partir da análise da referida tabela, considerando-se que os mesmos testemunhos foram ensaiados com a mesma idade, verifica-se que a resistência à tração obtida nos ensaios $(2,68)$ foi sensivelmente menor que a resistência à tração estimada $(3,68)$. Isso pode ser decorrente da perda de aderência, em consequência às microfissuras provocadas pela RAA.

Adicionalmente foram realizados ensaios de ultrassom para a obtenção do módulo de elasticidade dos testemunhos.

A Tabela 4 apresenta os resultados de medições de velocidade $\mathrm{V}(\mathrm{m} / \mathrm{s})$ obtidos em ultrassom, bem como sua correlação com o módulo de elasticidade dinâmico medido e determinado com base na NBR 6118,

\section{$\mathrm{Ec}=5.600 \mathrm{x} \mathrm{fc} 1 / 2$.}

Tabela 4: Resultados comparativos entre os módulos de deformação dinâmicos (medido x estimado)

\begin{tabular}{ccccc}
\hline $\mathbf{C P}$ & $\mathbf{I}(\mathbf{m})$ & $\mathbf{T}(\mathbf{U S})$ & $\mathbf{V}(\mathbf{m} / \mathbf{s})$ & $\mathbf{\& K}(\mathbf{M P a})$ \\
\hline 1 & 0,164 & 39,6 & 4140 & 22,90 \\
2 & 0,178 & 43,2 & 4120 & 22,30 \\
3 & 0,135 & 34,7 & 3890 & 17,1 \\
4 & 0,111 & 27,7 & 4010 & 19,2 \\
5 & 0,114 & 28,3 & 4030 & 19,7 \\
\hline
\end{tabular}

$$
\begin{aligned}
& \mathbf{T}=\text { Tempo } \\
& \mathbf{V}=\text { Velocidade } \\
& \boldsymbol{\&} \mathbf{K}=\text { Resistência do equipamento } \\
& \mathbf{U S}=\text { microsegundos }
\end{aligned}
$$

Mais uma vez, verifica-se uma considerável diminuição entre os resultados medidos e os estimados, conforme pode ser observado nos módulos de deformação. Isso ocorre devido à microfissuração presente nos testemunhos que, embora não seja muito percebida nos ensaios de resistência à compressão, afeta de forma relevante tanto o módulo de deformação quanto a resistência à tração.

\section{Análise do Problema}

As estruturas analisadas correspondem a blocos de fundação, com seção retangular e triangular, conforme ilustrado na Figura 16. 


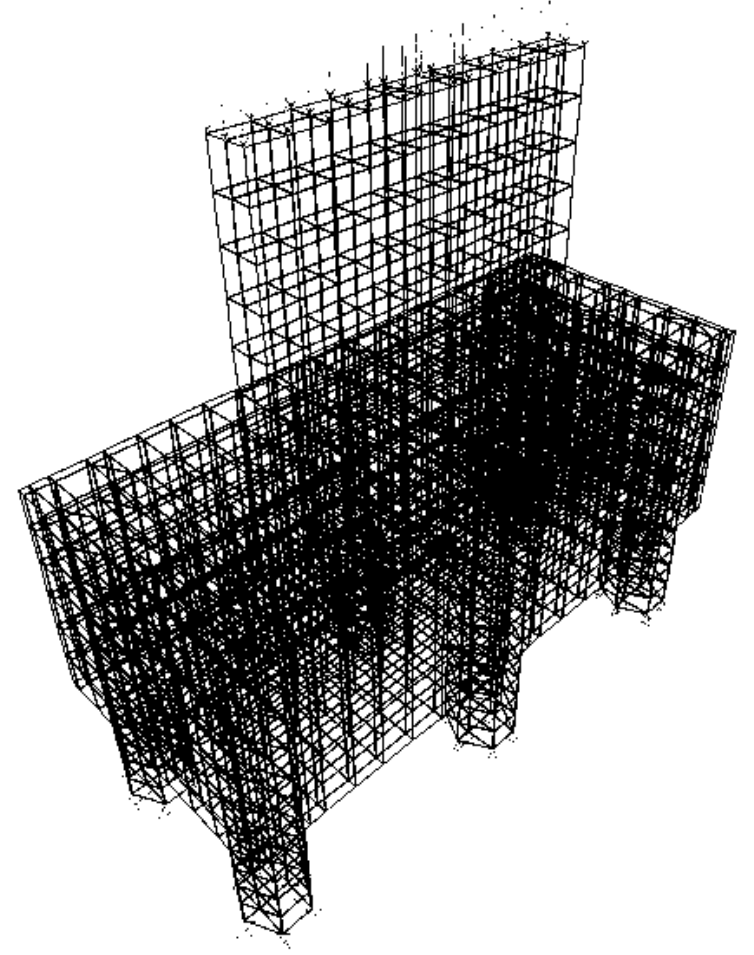

Figura 16: Discretização dos blocos mais carregados da fundação

As dimensões dos elementos blocos, pilares e estaca foram mensuradas in loco. Convém destacar ainda, que o bloco retangular está assentado em seis estacas com seção circular de $50 \mathrm{~cm}$ de diâmetro. As cargas inferidas através da área de influência sobre cada pilar foram estimadas em 560 tf para o bloco retangular. De forma análoga foi estudado o bloco triangular, que não será analisado nesse artigo.

Aplicando-se um modelo de SAP2000 versão15, aos blocos, considerando o sistema de barras comprimidas e tracionadas, tem-se um conjunto que funciona como sistema de bielas.

Assim, na parte superior, observam-se tensões de compressão com valor máximo de $-0,82 \mathrm{MPa}$. E, na parte inferior, tensões de tração com valor máximo registrado de 1,47MPa. Em cima da estaca central, verifica-se a maior tensão de tração, correspondente a $1,85 \mathrm{MPa}$, correspondendo à situação de um apoio central de uma viga.

A Figura 17 representa uma fatia central na direção da maior dimensão do bloco, coincidindo com o pilar. Na fibra inferior, observa-se a máxima tensão de tração de 1,26 MPa. Na fibra superior do bloco, na ligação do pilar, tem-se a tensão de compressão de -3,11MPa. Na ligação bloco/pilar ocorre uma condição de confinamento do pilar no bloco.

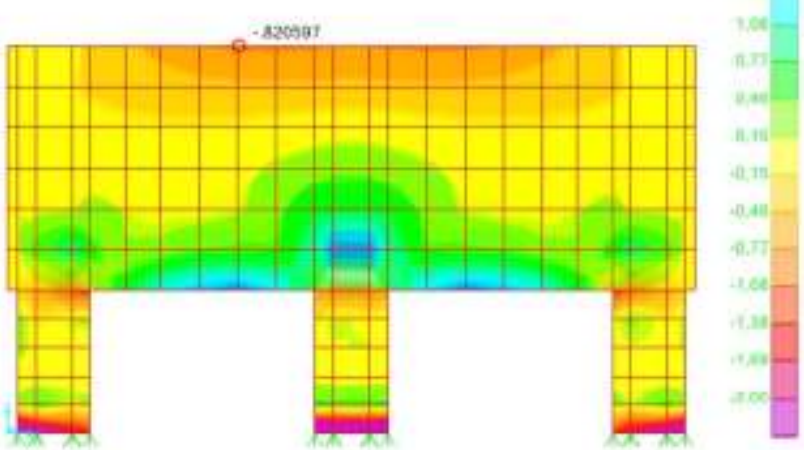

Figura 17: Representa fatia central na direção da maior dimensão do bloco coincidindo com o pilar

Na Figura 17, as cores mais quentes (vermelho) indicam tensões de tração, e as mais frias (de azul a amarelo) indicam regiões de compressão no interior do bloco.

Após a análise dos dois blocos, conclui-se que, quando ocorre a RAA, tem-se que reforçar a base, devido ao acréscimo de tensões, e a solução a ser adotada deve ser estudada caso a caso. Usualmente, têm-se a barra de dywidage e os perfis de aço com malha, voltando os blocos a serem monolíticos, após concretados, como foram projetados para funcionar inicialmente.

O reforço é feito através das seguintes etapas: escavação no entorno, limpeza das fissuras, colocação de armaduras de reforço, formas, limpeza interna com ar comprimido, injeção com epoxi, grauteamento para ligação do concreto antigo com o novo, colocação de armaduras e concretagem de todo o conjunto, conforme projeto de recuperação. Também devem ser colocados perfis nas três direções do bloco, a fim de reforçar e proteger os locais onde existem maiores tensões.

\section{Considerações Finais}

Os resultados do estudo de caso aqui abordado, com a combinação das análises e investigações realizadas nos dois tipos de blocos de fundação do edifício, mostraram que a origem das fissuras encontradas decorre da reação álcali-agregado do concreto utilizado nesses blocos.

Embora esse quadro fissuratório observado nos dois tipos de blocos mais carregados (dois blocos retangulares com seis estacas e dois blocos triangulares de três estacas), posicionados na parte frontal do edifício, possa ser interpretado como intenso, as tensões solicitantes nestes blocos são consideradas de baixa intensidade.

Apesar de não apresentarem risco de ruína ou colapso da edificação, no nível atual em que se encontram os 
blocos de fundação é prudente combater o desenvolvimento e a ampliação do quadro de fissuras existente, visto que essas fissuras possibilitam ações deletérias no concreto e nas armaduras dos blocos.

Para combater o avanço desse quadro fissuratório, restabelecendo a monoliticidade dos blocos e colmatando as fissuras abertas para evitar as ações deletérias potenciais, recomenda-se a execução de um projeto de reforço que promova estas ações.

Estudos comprovam que, após os procedimentos de reforço citados no item 3 , a probabilidade de reaparecer a RAA é mínima, assim como o surgimento de novas patologias. Destaque-se, entretanto, a importância da manutenção preventiva e das inspeções periódicas a cada dois anos.

\section{Referências}

[1] C.W. de A.P. SOBRINHO, A. V. MELO, e A. C. V. Carmo. Relatório Técnico ${ }^{\circ}$ 105479, ITEP, 2014.

[2] M. PECCHIO e A.F. BATTAGIN. Relatório de Ensaio $\mathrm{N}^{0} 93541$ - Análise petrográfica para verificação da potencialidade reativa de agregados em presença de álcalis do concreto, baseados nas normas: ASTM C 856-04 e ABNT NBR 155773/08 ABCP-SP - Associação Brasileira de Cimento Portland. São Paulo-SP, 2014.

[3] F.R. BARBOSA e C.W. de A.P. SOBRINHO. Reação álcali-agregado: caracterização e estudos da influência no maciço de uma barragem de concreto gravidade. Simpósio Sobre Reatividade Álcali-Agregado em Estrutura de Concreto. Anais.Comitê Brasileiro de Barragens, Furnas Centrais Elétricas, Goiânia, Goiás, 1997.

[4] D.C.C. Dal MOLIN. Contribuição ao estudo das propriedades mecânicas dos concretos de alta resistência com e sem aditivos de microssílica. Tese de doutorado, Universidade de São Paulo, São Paulo-SP, 1995.

[5] J.P. FIGUERÔA e T. W. C. de ANDRADE. O ataque da reação álcali agregado sobre as estruturas de concreto: a descoberta pioneira da ocorrência do problema em fundações de pontes e edifícios na região metropolitana do Recife-PE. Ed. Universitária da UFPE, Recife-PE, 2007. 228 p.

[6] L.E. LOPES. Modelagem mecânica e numérica da reação álcali-agregado com aplicação a barragens de concreto. Tese de doutorado, COPPE- Univer- sidade Federal do Rio de Janeiro, Rio de JaneiroRJ, 2004.

[7] F.S MONHOZ e J.S. GIONGO. Análise do comportamento de blocos de concreto armado sobre estacas submetidos à ação de força centrada. Dissertação de Mestrado, Escola de Engenharia de São Carlos- USP, São Carlos-SP, 2004.

[8] G.A. SILVA e R.A. OLIVEIRA. Recuperação de blocos de coroamento afetados pela reação álcaliagregado. Dissertação de mestrado Universidade Católica de Pernambuco, Recife-PE, 2007.

[9] E.A.O. GOMES , R.A. OLIVEIRA e A.O.C. FONTE Recuperação estrutural de blocos de fundação afetados pela reação álcali-agregado - a experiência do Recife. Dissertação de mestrado Universidade Católica de Pernambuco, Recife-PE, 2008. 